“C 2019 IEEE. Personal use of this material is permitted. Permission from IEEE must be obtained for all other uses, in any current or future media, including reprinting/republishing this material for advertising or promotional purposes, creating new collective works, for resale or redistribution to servers or lists, or reuse of any copyrighted component of this work in other works." 


\title{
Towards a novel framework of barriers and drivers for digital transformation in industrial supply chains
}

\author{
Thorsten Lammers ${ }^{1}$, Laura Tomidei ${ }^{1}$, Andrea Trianni ${ }^{1}$ \\ ${ }^{1}$ Faculty of Engineering and IT, University of Technology Sydney, 2007 Ultimo, Australia
}

\begin{abstract}
-
Businesses across all sectors are facing the complexity of an increasingly digital economy. Digital transformation offers vast opportunities to businesses and entire supply chains. While many investments are targeted at the organization level, the supply chain perspective can lead to even greater impacts on business performance. However, as supply chains involve interconnections between multiple actors, comprehensive digitalization initiatives at this level are very complex. Several strategic factors affect decision-making around digital investments. For this reason, a framework that categorizes all these factors is needed in order to help managers build digitalization strategies for their supply chains.
\end{abstract}

In this paper, based on a review of existing literature, we give indications for a framework encompassing barriers to and drivers for digital transformation in the context of industrial supply chains. Our framework preliminarily allocates these factors by using two dimensions. The first one classifies them using several categories: financial, knowledge and skills, regulatory, technological, market, organizational, and cultural. The second dimension classifies determinants at the level on which actions can be made, i.e. market, supply chain, or organization. The framework can support organizations to exploit the opportunities provided by digitalization of supply chains and will help managers understand the complexity involved.

\section{INTRODUCTION}

Digital transformation offers tremendous opportunities to companies of all sectors and supply chains. Digital transformation is defined as "the use of new digital technologies (social media, mobile, analytics or embedded devices) to enable major business improvements (such as enhancing customer experience, streamlining operations or creating new business models)" [1].

As companies participate in extended supply chains, the model for creating business value has dramatically changed. In this context, operational efficiency and greater profitability are the result of improved visibility and greater collaboration between the actors of the supply chain. Moreover, authors acknowledge that competitiveness is nowadays being played more and more at a system level, rather than that of a single company [2]. Digitalization is a means to achieve greater levels of cooperation and the associated benefits [2]. Focusing on the supply chain perspective, Bowersox, Closs, \& Drayer [2] claim that "true supply chain excellence will only come from making a digital business transformation". A transformation exploits all that technology has to offer, facilitates supply chain collaboration, and leads to new levels of operational excellence. More recently, Bughin, LaBerge, \& Mellbye [3] have shown that the digitalization of supply chains can deeply boost revenues and EBIT growth. In their study, the authors claim that full digitalization of supply chains contributes to two-thirds of the total revenue growth and more than $75 \%$ to the annual EBIT [3]. However, so far only few supply chains have taken full advantage of the potential of digital technologies [4]. In fact, only $2 \%$ of companies report to focus their digital strategies on the whole supply chain [3]. The slow adoption of digitalization across supply chains possibly leads to two main conclusions: Firstly, there are some barriers preventing companies from implementing digitalization strategies throughout the whole supply chain. Secondly, some facilitating elements might help supply chains and companies in the future towards their digital transformation. Because of the low adoption of digital technologies in supply chains, it is essential for managers to be aware of barriers and facilitators of digitalization. The supply chain perspective includes the interaction of multiple actors which causes a high level of complexity. Thus, the present study aims at contributing to the academic discussion by taking first steps towards a novel framework describing a set of barriers and drivers of digital transformation for the context of supply chains. The framework aims to contribute by helping managers understand the level of complexity related to the implementation of digital transformation strategies throughout the supply chain. Indeed, the influenceability of the complexity that businesses face depends on where barriers and drivers are located. For example, if the lack of a suitable infrastructure is considered as a barrier, businesses may find hard to exercise any influence. Specifically, if the cause of complexity is not influenceable, employing strategies that handle the complexity could be the best response. On the other hand, businesses can apply strategies to reduce the complexity when it is influenceable in the short term, and strategies to avoid complexity in the future when it is influenceable in the long run [5].

The remainder of the paper is structured as follows: In the next section, we provide a description of the methodology that has been applied. Then, we offer a preliminary description of the resulting framework and present its categories. After that, we provide a validation of the framework by assessing it against related previous efforts in literature. Finally, we discuss the findings and close the paper by looking at potential activities that may follow this research. 


\section{Methodology}

The goal of the research is to define a framework in which barriers and drivers of digital transformation in a supply chain context can be clustered. The main purpose of listing the factors preventing organizations to digitally transform is to understand whether companies can take any actions to lower barriers or exploit drivers. The framework we aim to produce is comprised of two dimensions (see Table I), one related to the level of origin where factors can reside, and the other related to the organizational category they can belong to. In order to define the first dimension (level of origin), we have used the model employed by Heilig, Lalla-Ruiz, \& Voß [6], which is derived from Game Theory principles [7]). Since digitalization is an innovative and transformative process involving multiple strategies and players, it can be modelled by using the organizational level in which different interactions occur. These levels can be distinguished in intra-level, inter-level, and metalevel. Intra-level interactions occur within the frame of the organization. Inter-level interactions involve other organizations that can be either competitors or collaborators. For the study purpose, this level represents the supply chain dimension. Finally, meta-level interactions are high-level and they include policy-makers and governments [6].

\begin{tabular}{|c|c|c|c|c|}
\hline & \multicolumn{3}{|c|}{ Level of origin } \\
\hline & & Intra-level & Inter-level & Meta-level \\
\hline \multirow{4}{*}{ 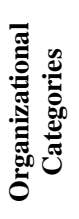 } & Category A & & & \\
\hline & Category B & & & \\
\hline & Category C & & & \\
\hline & Category D & & & \\
\hline
\end{tabular}

TABLE I. FRAMEWORK TEMPLATE

The second dimension (organizational categories) has been defined through a methodology that consists of three steps (see Figure I). In Step 1, we perform a systematic literature review to identify the studies focusing on barriers and drivers in digital transformation and innovation contexts. We have encompassed in our research either studies categorizing the factors in a more (or less) structured framework, mentioned in a list, or even just described throughout the text. The results provided by the methodology have been filtered according to the research scope. Thus, only those related to digital transformation and applicable to the supply chain context have been considered as relevant (Step 2). By analyzing these studies, we extracted the categories in which the authors have framed barriers and drivers (Step 3).

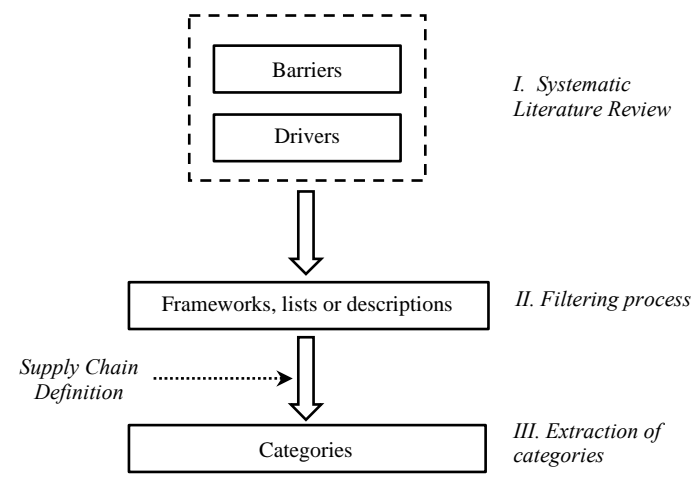

FIGURE I. THREE STEPS METHODOLOGY

\section{STEP 1. Literature Review}

In order to identify the factors that prevent or facilitate organizations and supply chains to digitally transform, a literature review has been applied following the methodology suggested by Levy \& Ellis [8]. To query quality scholarly literature, the database employed is SCOPUS ${ }^{\circledR}$. In the context of this study, barrier is defined as an obstacle preventing access and driver is defined as a facilitator, i.e. a factor that enables groups and organizations to work more effectively [10]. In general, the study investigates the determinants of digital transformation, defined as factors that decisively affect the nature or outcome of something. The keywords used have been derived from the definitions of barriers, drivers and determinants and they are displayed in Table II. The results have been filtered by source type - article or proceedings - and by subject area computer science, business, and engineering.

\begin{tabular}{|c|c|c|c|}
\hline & \multicolumn{3}{|c|}{ Keywords } \\
\hline \multirow{6}{*}{ 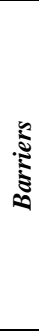 } & $\begin{array}{l}\text { Barriers Digital } \\
\text { Transformation }\end{array}$ & \multirow{15}{*}{ OR } & $\begin{array}{l}\text { Barriers Digital } \\
\text { Transformation Supply Chain }\end{array}$ \\
\hline & $\begin{array}{l}\text { Barriers Digital } \\
\text { Innovation }\end{array}$ & & $\begin{array}{l}\text { Barriers Digital Innovation } \\
\text { Supply Chain }\end{array}$ \\
\hline & Barriers ICT & & Barriers ICT Supply Chain \\
\hline & $\begin{array}{l}\text { Obstacles Digital } \\
\text { Transformation }\end{array}$ & & $\begin{array}{l}\text { Obstacles Digital } \\
\text { Transformation Supply Chain }\end{array}$ \\
\hline & $\begin{array}{l}\text { Obstacles Digital } \\
\text { Innovation }\end{array}$ & & $\begin{array}{l}\text { Obstacles Digital Innovation } \\
\text { Supply Chain }\end{array}$ \\
\hline & Obstacles ICT & & Obstacles ICT Supply Chain \\
\hline \multirow{6}{*}{$\stackrel{\vdots}{\vdots}$} & $\begin{array}{l}\text { Facilitator Digital } \\
\text { Transformation }\end{array}$ & & $\begin{array}{l}\text { Facilitator Digital } \\
\text { Transformation Supply Chain }\end{array}$ \\
\hline & $\begin{array}{l}\text { Facilitator Digital } \\
\text { Innovation }\end{array}$ & & $\begin{array}{l}\text { Facilitator Digital Innovation } \\
\text { Supply Chain }\end{array}$ \\
\hline & Facilitator ICT & & Facilitator ICT Supply Chain \\
\hline & $\begin{array}{l}\text { Enabling factors Digital } \\
\text { Transformation }\end{array}$ & & $\begin{array}{l}\text { Enabling factors Digital } \\
\text { Transformation Supply Chain }\end{array}$ \\
\hline & $\begin{array}{l}\text { Enabling factors Digital } \\
\text { Innovation }\end{array}$ & & $\begin{array}{l}\text { Enabling factors Digital } \\
\text { Innovation Supply Chain }\end{array}$ \\
\hline & Enabling factors ICT & & $\begin{array}{l}\text { Enabling factors ICT Supply } \\
\text { Chain }\end{array}$ \\
\hline \multirow{3}{*}{ 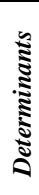 } & $\begin{array}{l}\text { Determinants Digital } \\
\text { Transformation }\end{array}$ & & $\begin{array}{l}\text { Determinants Digital } \\
\text { Transformation Supply Chain }\end{array}$ \\
\hline & $\begin{array}{l}\text { Determinants Digital } \\
\text { Innovation }\end{array}$ & & $\begin{array}{l}\text { Determinants Digital } \\
\text { Innovation Supply Chain }\end{array}$ \\
\hline & Determinants ICT & & $\begin{array}{l}\text { Determinants ICT Supply } \\
\text { Chain }\end{array}$ \\
\hline
\end{tabular}

TABLE II. KEYWORDS 


\section{STEP 2. Filtering process}

In order to identify the set of relevant papers from the results provided by the literature, a filtering process has been applied. For each result we have analyzed title, abstract and body respectively to assess the relevancy. As a result, the set of results has been narrowed down to sources providing relevant information about digital transformation in supply chain contexts. Supply chain is defined as "a set of three or more companies directly linked by one or more of the upstream and downstream flows of products, services, finances, and information from a source to a customer" [9]. Because supply chains include different companies, the factors affecting the adoption of digital strategies within the company can also affect the adoption of these on a supply chain level. Many studies in the current literature have focused on barriers for the adoption of digital technologies in the company context. These studies have been considered as relevant to the research purposes, as the framework we aim to develop classifies determinants also by level of origin. This is included in the intra-level that refers to the organizational context. Finally, it is important to note that most of the results provided by the literature focus on specific industries or countries. However, the aim of the research is to provide a framework that is universally applicable. Therefore, it is necessary to define categories in which barriers and drivers in any supply chain context can be identified.

\section{STEP 3. Extraction of categories}

The literature review provides results displayed in different formats. Those can be either lists, tables or detailed descriptions. From these we extracted and derived recurrent categories in which barriers and drivers can be grouped. While the categories are quite general (e.g. organizational, cultural, technological), some subcategories are specific to the research scope pursued in the paper and they are not applicable to all contexts. As the research aims to be universally applicable, only categories that are universally applicable have been considered.

\section{Results}

The following section discusses the results by illustrating first aggregated outcomes generated by the application of the methodology, and then describing the categories that have been identified.

\section{METHODOLOGY OUTCOMES}

The methodology provided 2061 results. After the filtering process outlines in STEP 2 above, 59 have been considered as relevant for the study purpose (17 conference papers and 42 journal articles). The keywords that provided the largest number of results are 'barrier' (27 results) and 'determinants' (15 results).

\section{CATEGORIES}

As mentioned earlier, barriers and drivers can be clustered by category and level of origin. While the different levels have been defined already (intra-level, inter-level and meta-level), the categories have been identified through the application of the methodology described above. Together, these two dimensions allow clustering barriers and drivers of digital transformation in supply chain contexts. The categories are illustrated in Table III and presented below.

\begin{tabular}{|l|l|l|l|l|}
\hline \multicolumn{2}{|c|}{} & \multicolumn{3}{c|}{ Level of origin } \\
\cline { 3 - 5 } & Intra-level & Inter-level & Meta-level \\
\hline \multirow{4}{*}{} & Financial & & & \\
\cline { 2 - 5 } & Knowledge \& skills & & & \\
\cline { 2 - 5 } & Regulatory & & & \\
\cline { 2 - 5 } & Technological & & & \\
\cline { 2 - 5 } & Environmental & & & \\
\cline { 2 - 5 } & Organizational & & & \\
\cline { 2 - 5 } & Cultural & & & \\
\hline \multirow{2}{*}{} & & & & \\
\hline
\end{tabular}

TABLE III. PRELIMIARY FRAMEWORK

\section{a. Financial}

Some of the most recurrent barriers and drivers throughout the literature are represented by financial factors. In this category, the most cited barrier at the intra-level is the high cost of system improvements. This generally refers to the high costs of innovation [10] and investment costs [11] [12], but it also includes high costs of digital tools, of setting up equipment [13] and implementation [14]. All these factors refer to the costs associated with the implementation of digital technologies being deemed by companies as too high.

Another common issue companies face is the lack of funding, either internal (intra-level) or external (meta-level). The lack of internal funding refers to the insufficient budget for digital innovation [14] [13], that also includes team training and R\&D [13]. On the other hand, the lack of external funding includes both lack of public funds and assistance, and lack of venture capital [10]. Accordingly, the availability of external funding, including government support, has been mentioned as a facilitator. A supportive national environment for the diffusion of new technologies has a positive effect on companies [15]. Finally, another financial category relates to the return on investment. In some cases, cost-benefits analyses are difficult to formulate [12] and these uncertainties are due to the lack of demonstrated business cases justifying the investment [16]. In some other cases, the problem is not related to the uncertainty of the return on investment. However, the short-term economic and financial policies [10] or the need for immediate return [14] represent an obstacle.

\section{b. Knowledge and skills}

Another recurrent barrier throughout the literature is represented by the lack of skills and knowledge. Companies are not able to find personnel with the right skills either within the company (intra-level) or on the market (meta-level).

The personnel are inadequate to implement digital innovation [14], as roles such as data scientist and other IT figures are often not available in the company [12]. 
On the other hand, sometimes talents and capabilities are missing from the market [16] or the complexity brought by new technologies requires new skills [14]. The competition for IT talents is very high and recruiting qualified staff is difficult [12].

Similarly, a recurrent facilitator is represented by skills and previous knowledge within the organization (intra-level). Human resources are one of the assets that influence the effectiveness of ICT the most [17]. This both refers to managerial knowledge and mindset [18] [19] [20] and workers' skills and educational background [21]. As a result, computer skills, commitment to ICT and enjoyment of learning positively influence the adoption of new technologies [11], while previous knowledge can generate know-how that facilitates to overcome the barriers that companies face [17].

In general, technology competence, comprising the organization's internal technology resources as well as technology infrastructure and IT skills [15], is considered an important driver of digital transformation. In fact, IT infrastructure and IT skills are complementary dimensions leading to greater effectiveness in value-chain activities. The infrastructure provides the base on which digital technologies can be implemented through the necessary skills [22].

\section{c. Regulatory}

The regulatory environment can represent an important external obstacle at meta-level in some cases. The lack of standards and frameworks [23] [24] as well as regulatory limitations due to hindering policies and regulations [10] [25] can be a consistent external barrier.

On the other hand, governments' actions can also be a driver for digital transformation in the form of support to the deployment of innovation through incentives that facilitate the adoption of digital technologies [26] for different purposes.

\section{d. Technological}

One of the most common technological barriers at meta-level is represented by privacy and security concerns around digital technologies and lack of infrastructure. Security issues include concerns on confidentiality [13], fear of fraud [14], security and privacy [23] [16]. Similarly, the lack of IT infrastructure [11] or the lack of the technology needed [10] [13] have been found to be very common throughout the studies. In other cases, the issue is not represented by the lack of the technology, rather by its maturity level and limitations [13] [12] [24].

\section{e. Environmental}

From the businesses' external environment, the most important barrier for the supply chain perspective (intra-level) is the lack of collaboration and cooperation between actors. Digital technologies allow supply chains to achieve higher levels of collaboration with the associated benefits [2]. However, studies have mentioned the lack of collaboration and cooperation between the supply chain actors as a barrier to the implementation of digital transformation [25] [10] [13].
Integrating with vendors' and suppliers' systems throughout the supply chain is essential to unlock the full potential provided by the digitalization of the whole supply chain.

Another common factor arising from the meta-level that pushes organizations to adopt new technologies is competitive pressure. This refers to the pressure from the market on using new technologies, and can be represented by competitors that have already adopted digital technologies [15].

A supply chain context (inter-level) involves interconnected relations of multiple actors that introduce specific facilitating factors. Specifically, organizations may be pushed by other actors in the supply chain to adopt technologies, or may be the first adopters. The first case is the result of external pressures, which are similar to competitive pressures, but quite specific to the supply chain context: this includes pressures from the buyer or the supplier, or trading partners [27]. The second case occurs when a company wants to adopt a new IT system and has to face the issues arising by the inter-relations of the supply chain. In this case, two possible situations can facilitate the uptake of new technologies: the first one is the partner readiness, i.e. the degree to which system used by trading partners, up and down the value chain, can integrate with the company's one [15]. In this sense, cooperation and collaboration between partners is an essential component for the innovation uptake [25]. The second one is to overcome the issues derived by the interconnections with multiple actors by employing a system that is discrete and does not require any integration [26]: this can be possible by using systems that support an information exchange standard facilitating the communication between multiple ICT systems while providing independence to each of them [11].

\section{f. Organizational}

In order to make decisions that involve the transformation of business process within the organization, the perception of relative advantage is fundamental. This is defined by Zhu, Dong, $\mathrm{Xu}, \&$ Kraemer [15] as 'the degree to which an innovation can bring benefits to an organisation' by reducing costs and increasing sales.

Strategic factors have been considered among organizational aspects, as the strategy is strictly related to the organizational structure and processes. Weak innovation strategies are often considered a barrier to the efficient development of digital transformation processes [16] [10] [13]. On the other hand, as organizations are characterized by specific processes, practices and value systems, the degree to which new technologies are compatible with them play a significant role in the uptake of new technologies [15] [27].

Finally, another recurrent organizational aspect emerging from the literature is the lack of time within the organization (intralevel). This could be either the lack of time spent on specific activities such as planning [14], or general time constraints to innovation initiatives [10].

\section{g. Cultural}

In order to address the changes needed to implement digital transformation, innovation culture [12] and an environment 
allowing for open discussion [11] within the companies (intralevel) play a significant role. An unsupportive organizational culture can represent an obstacle when introducing innovation [10]. This can be further divided into specific cultural aspects such as poor organizational attitude towards innovation, insufficient team commitment and adversarial relationship among the staff [13]. Another important factor contributing to unsupportive organizational culture originates from the managerial staff and the lack of leadership in driving digital transformation. This can be due either to the lack of support of managerial staff, or the lack of managers to supervise digital innovation [13]. In both cases, the result is a lack of or insufficient time spent on planning and coordination [24] [14] creating an obstacle to digital innovation.

Two other recurrent components mentioned as cultural barriers at intra-level are organizational inertia and lack of interest. These can be seen also as psychological barriers characterizing the culture of an organization. Organizational inertia - defined as fear of or resistance to change - can create a significant obstacle to digital transformation, that by definition involves changes within the organization processes [1]. Fear of change can also involve many aspects including fear of work, product, process or marketing changes [13]. On the other hand, lack of interest in innovation [11] and in the knowledge of digital technology represents a different issue, as it arises from the individual value orientation, that can also develop in a persistent and negative attitude toward innovation [14].

\section{DISCUSSION AND OUTLOOK}

The need for a framework that classifies barriers and drivers arises from the fact that the available studies in the current literature mainly focus on the organizational context. However, as businesses are part of extended supply chains, the way they create value has changed. Visibility, integration and collaboration between partners allow obtaining real operational efficiency and financial improvements. Digital transformation is the means to achieve true supply chain excellence [2].

Despite the big potential of supply chain digitalization, very few companies (only 2\%) report to adopt this perspective [3]. Since a comprehensive framework classifying barriers and drivers for digital transformation does not yet exist, this study aims at helping managers develop more effective strategies addressing the complexity arising from supply chains. It offers a contribution in more clearly understanding both barriers and drivers and in indicating these factors are located. As a result, strategies can indeed be formulated more precisely and managers may know whether to handle, reduce or avoid the complexity generated by the interaction of barriers and drivers $[5]$.

The framework provided by this study has been defined using theoretical bases. Future research can aim to verify the results by conducting an empirical study that address the factors preventing or facilitating businesses to focus their digital strategies on supply chains.

\section{REFERENCES}

[1] M. Fitzgerald, N. Kruschwitz, D. Bonnet and M. Welch, "Embracing In collaboration with Digital Technology - a new strategic imperative," MIT Sloan Management Review, vol. 55 , no. 2, p. 1, 2013.

[2] E. Massaroni, A. Cozzolino and E. Wankowicz, "Sustainability in supply chain management-a literature review.," Sinergie, vol. 98, 2015.

[3] D. Bowersox, D. Closs and R. Drayer, "THE DIGITAL TRANSFORMATION: Technology and Beyond," Supply Chain Management Review, vol. 9, no. 1, pp. 22-29, 2005.

[4] J. Bughin, L. LaBerge and A. Mellbye, "The case for digital reinvention," McKinsey Quarterly, pp. 1-15, 2017.

[5] E. Gezgin, X. Huang, P. Samal and I. Silva, "Digital transformation: Raising supply-chain performance to new levels," 2017. [Online]. Available: https://www.mckinsey.com/business-

functions/operations/our-insights/digital-transformationraising-supply-chain-performance-to-new-levels. [Accessed October 2018].

[6] T. Lammers, Komplexitätsmanagement für Distributionssysteme: Konzeption eines strategischen Ansatzes zur Komplexitätsbewertung und Ableitung von Gestaltungsempfehlungen, BoD-Books on Demand, 2012.

[7] L. Heilig, E. Lalla-Ruiz and S. Voß, "Digital transformation in maritime ports: analysis and a game theoretic framework," Netnomics, vol. 18, pp. 227-254, 2017.

[8] J. Von Neumann and O. Morgenstern, Theory of games and economic behavior, Princeton: Princeton University Press, 1953.

[9] Y. Levy and T. Ellis, "A Systems Approach to Conduct an Effective Literature Review in Support of Information Systems Research," Informing Science Journal, vol. 9, pp. 181-212, 2006.

[10] S. Kaner, Facilitator's guide to participatory decisionmaking, John Wiley \& Sons, 2014.

[11] J. T. Mentzer, W. DeWitt, J. S. Keebler, S. Min, N. W. Nix, C. D. Smith and Z. G. Zacharia, " Defining supply chain management," Journal of Business Logistics, vol. 22, no. 2, pp. 1-25, 2001.

[12] A. Hjalmarsson, P. Johannesson, G. Juell-Skielse and D. Rudmark, "BEYOND INNOVATION CONTESTS: A FRAMEWORK OF BARRIERS TO OPEN INNOVATION OF DIGITAL SERVICES," 2014.

[13] V. Peansupap and D. Walker, "Factors affecting ICT diffusion: a case study of three large Australian construction contractors," Engineering, construction and architectural management, vol. 12, no. 1, pp. 21-37, 2005.

[14] A. A. Pflaum and P. Golzer, "The IoT and Digital Transformation: Toward the Data-Driven Enterprise," IEEE Pervasive Computing, vol. 1, pp. 87-91, 2018.

[15] R. Ramilo and M. Embi, "Critical analysis of key determinants and barriers to digital innovation adoption among architectural organizations," Frontiers of Architectural Research, vol. 3, no. 4, pp. 431-451, 2014.

[16] S. Molinillo and A. Japutra, "Organizational adoption of digital information and technology: a theoretical review," The Bottom Line, vol. 30, no. 1, pp. 33-46, 2017.

[17] K. Zhu, S. Dong, S. Xu and K. Kraemer, "Innovation diffusion in global contexts: determinants of post-adoption 
digital transformation of European companies," European Journal of Information Systems, vol. 15, no. 6, pp. 601-616, 2005.

[18] D. Küsters, N. Praß and Y.-S. Gloy, "Textile Learning Factory 4.0 - Preparing Germany's Textile Industry for the Digital Future," Procedia Manufacturing, vol. 9, pp. 214221, 2017.

[19] A. Gargallo-Castel and M. Ramírez-Alesón, "Human resources as facilitators of the adoption of information and communication technologies," International Journal of Information Technology and Management, vol. 7, no. 4, pp. 405-420, 2008.

[20] C. Ranganathan, T. S. Teo and J. Dhaliwal, "Web-enabled supply chain management: Key antecedents and performance impacts," International Journal of Information Management, pp. 533-545, 2011.

[21] A. Zangiacomi, M. Sacco, E. Pessot, A. De Zan and M. Bertetti, "A Perspective for the Implementation of a Path Towards the Factory of the Future: The Italian Case," in 2018 IEEE International Conference on Engineering, Technology and Innovation , 2018.

[22] F. Bienhaus and A. Haddud, "Procurement 4.0: factors influencing the digitisation of procurement and supply chains," Business Process Management Journal, 2018.

[23] I. Giotopoulos, A. Kontolaimou, E. Korra and A. Tsakanikas, "What drives ICT adoption by SMEs? Evidence from a largescale survey in Greece," Journal of Business Research, vol. 81, pp. 60-69, 2017.

[24] K. K. K. \&. X. S. Zhu, "Electronic business adoption by European firms: a cross-country assessment of the facilitators and inhibitors," European Journal of Information Systems, vol. 12, no. 4, pp. 251-268, 2003.

[25] S. Karim, A. Al-Tawara, E. Gide and R. Sandu, "Is big data too big for SMEs in Jordan?," in Information Technology (ICIT), 2017 8th International Conference, 2017.

[26] A. Touray, A. Salminen and A. Mursu, "ICT barriers and critical success factors in developing countries," The Electronic Journal of Information Systems in Developing Countries, vol. 56, no. 1, pp. 1-17, 2013.

[27] V. Carlan, C. Sys, T. Vanelslander and A. Roumboutsos, "Digital innovation in the port sector: Barriers and facilitators," Competition and regulation in network industries, vol. 18, no. 1-2, pp. 71-93, 2017.

[28] H. Cripps and C. Standing, "The implementation of electronic health records: A case study of bush computing the Ngaanyatjarra Lands," International Journal of Medical Informatics, pp. 841-848, 2011.

[29] M. Ghobakhloo, D. Arias-Aranda and J. Benitez-Amado, "Adoption of e-commerce applications in SMEs," Industrial Management \& Data Systems, vol. 111, no. 8, pp. 1238-1268, 2011.

[30] S. F. Jahanmir and J. Cavadas, "Factors affecting late adoption of digital innovations," Journal of Business Research, vol. 88, pp. 337-343, 2018.

[31] G. Harindranath, R. Dyerson and D. Barnes, "ICT adoption and use in UK SMEs: a failure of initiatives?," Electronic journal of information systems evaluation, vol. 11, no. 2, 2008.

[32] M. I. Adamkolo, M. S. Hassan and S. Yusuf, "Determinants of Information Technology Adoption among Malaysian Farm-based Enterprises," Pertanika Journal of Social Sciences \& Humanities, vol. 24, no. 4, 2016.
[33] S. N. Y. L. S. \&. S. H. Lee, "Determinants of ICT innovations: A cross-country empirical study," Technological Forecasting and Social Chang, vol. 110, pp. 71-77, 2016

[34] R. Vidhyalakshmi and V. Kumar, "Determinants of cloud computing adoption by SMEs," International Journal of Business Information Systems, vol. 22, no. 3, pp. 375-395, 2016.

[35] A. S. Dhaigude, R. Kapoor and S. Ambekar, "A conceptual model for adoption of information communication technology in the travel and tourism industry. Tourism Recreation Research, 41(1), 49-59.," Tourism Recreation Research, vol. 41, no. 1, pp. 49-59, 2016.

[36] M. V. Alderete and L. H. Gutiérrez, "rivers of information and communication technologies adoption in Colombian services firms," International Journal of Business Information Systems, vol. 17, no. 4, pp. 373-397, 2014.

[37] S. C. Eze, H. O. Awa, J. C. Okoye, B. C. Emecheta and R. O. Anazodo, "Determinant factors of information communication technology (ICT) adoption by governmentowned universities in Nigeria: A qualitative approach," Journal of Enterprise Information Management, vol. 26, no. 4, pp. 427-443, 2013.

[38] M. Kyobe, "Investigating the key factors influencing ICT adoption in South Africa," Journal of systems and information technology, vol. 13, no. 3, pp. 255-267, 2011.

[39] P. Guerrieri, M. Luciani and V. Meliciani, "The determinants of investment in information and communication technologies," Economics of Innovation and new Technology, vol. 20, no. 4, pp. 387-403, 2011.

[40] A. Bayo-Moriones and F. Lera-López, "A firm-level analysis of determinants of ICT adoption in Spain," Technovation, vol. 27, no. 6-7, pp. 352-366, 2007.

[41] E. Kurti and D. Haftor, "Barriers and enablers of digital business model transformation," in The European Conference on Information Systems Management, 2015.

[42] B. Bailie and M. Chinn, "Effectively Harnessing Data to Navigate the New Normal: Overcoming the Barriers of Digital Adoption.," in Offshore Technology Conference, 2018.

[43] V. Ahmed, Z. Aziz, A. Tezel and Z. Riaz, "Challenges and drivers for data mining in the AEC sector," Engineering, Construction and Architectural Management, vol. 25, no. 11, pp. 1436-1453, 2018.

[44] A. O. U. Ozumba and W. Shakantu, "Exploring challenges to ICT utilisation in construction site management," Construction Innovation, 2018.

[45] B. Pikkemaat, M. Peters and C.-S. Chan, "eeds, drivers and barriers of innovation: The case of an alpine communitymodel destination," Tourism management perspectives, vol. 25, p. 5363, 2018.

[46] P. A. S. Ern, N. Kasim, M. A. N. Masrom and G. K. Chen, "Overcoming ICT Barriers in IBS Management Process in Malaysia Construction Industry.," in MATEC Web of Conferences, 2017.

[47] E. Alreshidi, M. Mourshed and Y. Rezgui, "Factors for effective BIM governance," Journal of Building Engineering, vol. 10, pp. 89-101, 2017.

[48] P. J. Makiwa and R. Steyn, "ICT adoption and use in Zimbabwean SMEs," in IST-Africa Week Conference, 2016.

[49] M. C. Cant and J. A. Wiid, "Internet-Based ICT Usage By South African SMEs: The Barriers Faced By SMEs," Journal of Applied Business Research, vol. 32, no. 6, p. 1877, 2016. 
[50] C. A. Ardagna, P. Ceravolo and E. Damiani, "Big data analytics as-a-service: Issues and challenges," in IEEE International Conference, 2016.

[51] I. Harris, Y. Wang and H. Wang, "ICT in multimodal transport and technological trends: Unleashing potential for the future," International Journal of Production Economics, vol. 159, pp. 88-103, 2015.

[52] S. K. Kabanda and I. Brown, "E-Commerce Enablers and Barriers in Tanzanian Small and Medium Enterprises," The Electronic Journal of Information Systems in Developing Countries, vol. 67, no. 1, pp. 1-24, 2015.

[53] A. Scupola, "ICT adoption in facilities management supply chain: the case of Denmark," Journal of Global Information Technology Management, vol. 15, no. 1, pp. 53-78, 2012.

[54] M. Kapurubandara and R. Lawson, "SMEs in developing countries face challenges in adopting e-commerce technologies," in Digital EcoSystems and Technologies Conference, 2007.

[55] H. van Zon, "The digital economy: Challenges for central European industry," AI \& Society, vol. 15, no. 3, pp. 216-232, 2001.
[56] W. Sung, "Digital innovation and regulatory policy: Why does, development of digital technology not lead to innovation?," in Proceedings of the 19th Annual International Conference on Digital Government Research: Governance in the Data Age , 2018.

[57] M. Al-Ruithe, E. Benkhelifa and K. Hameed, "Key Issues for Embracing the Cloud Computing to Adopt a Digital Transformation: A study of Saudi Public Sector," Procedia computer Science, vol. 130, pp. 1037-1043, 2018.

[58] M. Wolf, A. Semm and C. Erfurth, "Digital Transformation in Companies-Challenges and Success Factors," in International Conference on Innovations for Community Services , 2018.

[59] G. Gravili, M. Benvenuto, A. Avram and C. Viola, "The influence of the Digital Divide on Big data generation within supply chain management," in nternational Journal of Logistics Management, 2018.

(References include not only in-text citations, but also key results of systematic literature review) 